\title{
Caminhos da sobrevivência psíquica à resiliência: um relato de caso
}

\author{
Pathways from psychic survival to resilience: a case report \\ Caminos de la supervivencia psíquica a la resiliencia: un relato de caso
}

Felipe de Luca Medeiros ${ }^{a}$

Bibiana Godoi Malgarim ${ }^{b}$

Lúcia Helena Machado Freitas ${ }^{c}$

a Universidade Federal do Rio Grande do Sul, Departamento de Psiquiatria e Medicina Legal - Porto Alegre RS - Brasil.

b Universidade Federal do Rio Grande do Sul, Programa de Pós-Graduação em Psiquiatria - Porto Alegre - RS - Brasil.

c Universidade Federal do Rio Grande do Sul, Departamento de Psiquiatria e Medicina Legal - Porto Alegre RS - Brasil.

DOI 10.5935/2318-0404.20190001

Instituição: Universidade Federal do Rio Grande do Sul

\section{Resumo}

Resiliência é um conceito ainda em evolução que procura compreender a capacidade de alguns indivíduos suportarem situações traumáticas de três maneiras principais: mantendo seu equilíbrio mental, retornando ao seu funcionamento prévio ou crescendo psiquicamente após o trauma. No contexto psicoterapêutico, é importante conhecer como auxiliar o indivíduo a percorrer os caminhos de um estado mental de adaptação ao trauma (sobrevivência psíquica) à resiliência. $O$ presente relato ilustra dificuldades enfrentadas nesse processo 
em psicoterapia de orientação analítica de um paciente com história de múltiplos traumas e problemas severos ao longo de seu ciclo vital. Destaca a importância do papel de tutor de resiliência exercido pelo psicoterapeuta, através de encontros emocionalmente genuínos e sensíveis que criam um espaço para que a dor seja acolhida e a resiliência "tecida" mediante narrativas que produzam experiências de reparação, facilitando a construção de novas bases de segurança e metamorfoseando feridas psíquicas em novos significados. Para o psicoterapeuta empreender essa função, o relato também delineia a importância de se compreender os fatores que dificultam o sujeito a percorrer esse caminho sem ajuda profissional, incluindo: déficit na aquisição de recursos internos na infância; tipo, intensidade, período do ciclo vital, contexto e significados do evento traumático; bem como carência de rede de apoio ou dificuldade ao mobilizá-la para narrar e encenar o trauma.

Palavras-chave: Resiliência; Trauma Psicológico; Psicoterapia

\begin{abstract}
Resilience is an evolving concept that tries to understand the ability of some individuals to endure traumatic situations in three main ways: maintaining their mental balance, returning to their previous functioning or growing psychically after the trauma. In the psychotherapeutic context, it is important to know how to help the individual to go through the pathways from a mental state of adjustment to trauma (psychic survival) to resilience. The present report illustrates difficulties faced in this process in psychoanalytic psychotherapy of a patient with history of multiple traumas and severe problems throughout his life cycle. It highlights the importance of the role of tutor of resilience performed by the psychotherapist, through emotionally genuine and sensitive encounters that set up a space for pain to be embraced and resilience "woven" by narratives that produce experiences of reparation, facilitating the development of new foundations of safety and metamorphosing psychic wounds into new meanings. For the psychotherapist to undertake this function, the report also delineates the importance of understanding the factors that hinder the individual to go through this pathway without professional help, including: deficit in acquisition of internal resources in childhood; type, intensity, life cycle period, context and meanings of the traumatic event; as well as lack of support network or difficulty in mobilizing it to narrate and enact the trauma.
\end{abstract}

Keywords: Resilience; Psychological Trauma; Psychotherapy

\title{
Resumen
}

Resiliencia es un concepto aún en evolución que busca comprender la capacidad de algunos individuos para soportar situaciones traumáticas de tres maneras principales: manteniendo su equilibrio mental, retornando a su funcionamiento previo o creciendo psíquicamente después del trauma. En el contexto psicoterapéutico, es importante conocer cómo ayudar al individuo a recorrer los caminos de un estado mental de adaptación al trauma (supervivencia psíquica) a la resiliencia. El presente relato ilustra dificultades enfrentadas en ese proceso 
en psicoterapia de orientación psicoanalítica de un paciente con historia de múltiples traumas y problemas severos en su ciclo vital. Destaca la importancia del papel de tutor de resiliencia ejercido por el psicoterapeuta, a través de encuentros emocionalmente genuinos y sensibles que crean un espacio para que el dolor sea acogido y la resiliencia "tejida" mediante narrativas que produzcan experiencias de reparación, facilitando la construcción de nuevas bases de seguridad y metamorfoseando heridas psíquicas en nuevos significados. Para el psicoterapeuta emprender esa función, el relato también delinea la importancia de comprender los factores que dificultan al sujeto a recorrer ese camino sin ayuda profesional, incluyendo: déficit en la adquisición de recursos internos en la infancia; tipo, intensidad, período del ciclo vital, contexto y significados del trauma; así como carencia de red de apoyo o dificultad al movilizarla para narrar y escenificar el trauma.

Palabras clave: Resiliencia; Trauma Psicológico; Psicoterapia

\section{Introdução}

A resiliência é um construto multidimensional, amplo e complexo que procura entender os mecanismos de resistência e superação às adversidades e traumas inerentes ao ciclo da vida humana. Tenta responder a perguntas como: por que pessoas expostas ao mesmo tipo de adversidade ou trauma se distanciam pelos diferentes caminhos da saúde e da doença; e como um evento doloroso considerado de menor intensidade, no senso comum, provoca em indivíduos diferentes as mais variadas reações, desde o retorno ao seu funcionamento usual ou melhor e, em outros, deterioração irreversível das capacidades. Entender o fenômeno da resiliência, como se desenvolve, quais seus empecilhos e facilitadores aumenta o aporte de recursos preventivos, bem como a compreensão para acréscimos na teoria e técnica de tratamentos mais efetivos com sobreviventes de traumas psíquicos.

A busca pela compreensão da resiliência levou ao crescimento vertiginoso de investigações sobre o tema publicados nas últimas décadas ${ }^{1}$. Contudo, a resiliência ainda é um construto multidimensional em desenvolvimento e, portanto, marcado pela pluralidade de definições que dificultam seu estudo, gerando divergências entre clínicos e pesquisadores. Para melhor compreender a evolução do construto da resiliência, apresentaremos a seguir a evolução das diferentes perspectivas de seu estudo, destacando-se: perspectiva do desenvolvimento infantil; perspectiva da teoria da personalidade; perspectiva biológica; e perspectiva do trauma, recuperação, reconfiguração e crescimento pós-traumático. Por fim, daremos ênfase ao enfoque psicanalítico, tendo como referencial maior aspectos da importante obra de Boris Cyrulnik.

As pesquisas iniciais sobre a resiliência partiram da compreensão do desenvolvimento infantil com enfoque no entendimento de por que algumas crianças apresentavam capacidade de uma adaptação bemsucedida ou de desenvolvimento saudável de competências sociais, acadêmicas e emocionais, por exemplo, mesmo frente a adversidades e traumas. Inicialmente os estudos usaram o enfoque da invulnerabilidade o que depois evoluiu para o conceito de resiliência. As pesquisas buscavam investigar os fatores protetivos por um lado e os de risco ou de vulnerabilidade do outro², sendo interessante observar que esses aspectos podem ser 
distintos para diferentes populações ${ }^{1}$. Destacam-se, entre os fatores de risco, o baixo nível socioeconômico; e, como um dos principais fatores protetivos para o desenvolvimento de características de resiliência, o apego seguro, conforme a teoria do vínculo parental de John Bowlby ${ }^{3,4}$.

A perspectiva da teoria da personalidade tenta entender a resiliência a partir do construto do ego e dos mecanismos de defesa visando a compreender os aspectos significativos e estáveis da personalidade que contribuem para a adaptabilidade ${ }^{2}$. Aqui, a resiliência pode ser vista como um traço da personalidade, ou seja, um "traço resiliente". Vaillant é um importante estudioso nessa área e observou a associação positiva entre resiliência e os mecanismos de defesa maduros como altruísmo, sublimação, supressão e humor ${ }^{5}$. Indivíduos resilientes são frequentemente caracterizados por terem atitudes positivas e senso de humor e serem otimistas, com enfrentamento ativo para resolver os problemas, manejar o estresse e controlar as emoções negativas ${ }^{3}$. Ainda sob essa ótica, um estudo mostra, por exemplo, três principais mecanismos de defesa como preditores de sintomatologia de transtorno de estresse pós-traumático em pacientes vítimas de trauma: racionalização, cisão e projeção, ou seja, mecanismos de defesa predominantemente imaturos ${ }^{6}$.

A perspectiva biológica busca compreender a relação da resiliência com: características inatas do temperamento; influência do ambiente no desenvolvimento cerebral; autor regulação emocional; e processamento cognitivo e sua relação com características de enfrentamento ${ }^{2}$. Um exemplo de investigação que integra esses conceitos é o de Simeon ${ }^{7}$, que observou que a resiliência foi positivamente associada com altos níveis de cortisol urinário, apego seguro, traço de personalidade de dependência de recompensa e performance cognitiva superior; e negativamente associada com traumas interpessoais na infância e com traço de personalidade de evitação de dano.

Por fim, a perspectiva do trauma, recuperação, reconfiguração e crescimento pós-traumático busca entender o fenômeno da resiliência no contexto de eventos violentos e ameaçadores à vida. Bonanno ${ }^{8}$, um autor de destaque nessa área, diferencia recuperação de resiliência, descrevendo recuperação como um processo de retornar a um estado saudável anterior e resiliência como a habilidade de permanecer num estado de equilíbrio frente a um trauma. Contudo, a característica de resiliência mais interessante que esse campo estuda é a de reconfiguração, definida como a capacidade de reagir à adversidade e sair fortalecido, enriquecido e com mais recursos psíquicos para dar conta de infortúnios ${ }^{9}$, mostrando que, em alguns casos, a adversidade ou o trauma podem melhorar o funcionamento e o bem-estar, uma vez que o enfrentamento efetivo de experiências adversas tem o potencial de promover novas habilidades de enfrentamento e o desenvolvimento de recursos pessoais e sociais ${ }^{2}$. Os indivíduos podem apresentar esse tipo de resiliência quando são capazes de reconfigurar suas cognições, mecanismos de defesa, crenças e comportamentos de tal forma que lhes permite adaptar-se a experiências traumáticas e, eventualmente, suportar fortalecidos traumas futuros. Este tipo de resiliência assemelha-se e coincide com o que mais recentemente vem se denominando crescimento pós-traumático. O crescimento pós-traumático é, sem dúvida, um resultado possível para os indivíduos que passam por um processo de reconfiguração ou mudanças favoráveis em seu mundo interno. Essa 
perspectiva reconhece que a resiliência a estressores futuros pode se desenvolver a partir das transformações que ocorreram com o enfrentamento de um evento traumático acontecido mais cedo na vida, preparando para as próximas adversidades ${ }^{10}$.

O estudo da resiliência a partir do referencial psicanalítico é recente e ainda há, portanto, escassez de pesquisas e publicações científicas sobre esse construto a partir desse referencial. Uma revisão sistemática que avaliou 11 estudos psicanalíticos sobre resiliência constatou que há convergência quanto à noção de que resiliência é um processo que vai além de adaptar-se pura e simplesmente; implica capacidade de prosperar, relaciona-se com capacidades intrapsíquicas e também com experiências emocionais primitivas. Sob essa concepção, a resiliência apresenta-se como característica que está profundamente imbricada não somente com o contexto social do sujeito, mas também se desenvolvendo a partir dele e com ele ${ }^{11}$.

No estudo da psicodinâmica da resiliência é importante destacar a obra de Boris Cyrulnik. Esse autor é considerado por alguns estudiosos um dos mais importantes escritores sobre o tema na atualidade. Sua biografia conta que ele foi uma criança francesa judia sobrevivente da II Guerra Mundial. Tornou-se médico, neuropsiquiatria e psicanalista com uma sensível e extensa produção científica. Em um de seus vários livros relembra Arquimedes: "Dê-me uma alavanca e um ponto de apoio e levantarei o mundo" como metáfora para a resiliência. Cyrulnik ${ }^{12}$ evidencia que para uma pessoa ser resiliente é necessário um longo caminho no qual três pontos são muito relevantes: (1) a aquisição de recursos internos que se desenvolvem nos primeiros meses de vida; (2) o tipo de agressão, de feridas de carência e sobretudo o significado e o contexto das mesmas; e (3) os encontros, as possibilidades de falar e encenar o trauma. Para este autor a resiliência se cria em função do temperamento da pessoa, de sua cultura e do tipo de suporte social de que dispõe.

Cyrulnik ${ }^{12}$ chama de guardiões ou tutores da resiliência, na trajetória resiliente, alguém, uma pessoa, um lugar, um acontecimento, uma obra de arte que provoque um renascer ou o retomar do desenvolvimento psicológico após um trauma, tal como um adulto que encontra uma criança e que assume para ela um significado de um modelo de identidade e provoca uma mudança em sua existência. Pode se tratar de um profissional ou não, mas invariavelmente de um encontro significativo com o outro, com o olhar do outro para sua dor - um meio ambiente que acolha a narrativa dos eventos e das emoções a eles atrelados. Resiliência é "tecida": não só pode ser encontrada na interioridade da pessoa ou em seu ambiente, mas entre os indivíduos em um processo íntimo com o ambiente social em que a pessoa é vista e ouvida. Assim, enfatiza o papel da oportunidade ao traumatizado de um espaço para narrativa e que todo o relato é uma defesa, uma legítima defesa, ou seja, todo o relato é um projeto de libertação. Não é uma volta ao passado, mas uma reconciliação com a própria história para aquele que navega pela resiliência. Como diria a filósofa alemã Hannah Arendt, "todas as dores podem ser suportadas se você as puser numa história ou contar uma história sobre elas"13. Cyrulnik ${ }^{14}$ considera que a resiliência é um remanejamento do psiquismo frente a uma situação traumática e ansiogênica. O autor afirma que toda vez que há uma desorganização - evento de ordem traumática - o sujeito é tomado pelas incessantes tentativas de reordenar os acontecimentos na busca pelo sentido. Inclui um trocadilho por meio da expressão Compulsão ao Sentido, fazendo menção ao original Compulsão à Repetição 
de Sigmund Freud, a fim de denominar uma "adaptação necessária", que ocorre como primeiro momento de enfrentamento, para depois a resiliência emergir como capacidade de criar um novo projeto de vida, não dissociado da vivência anterior.

Cyrulnik $^{12}$ alerta para a diferença entre sobrevivência psíquica e resiliência: a sobrevivência psíquica ou adaptação pode conter ou não resiliência. Assim havendo uma diferença nessas condições em termos de saúde mental. Uma trajetória resiliente é aquela na qual o traumatizado utiliza a lembrança de uma ferida para fazer dela uma ação dinâmica. $O$ trabalho psicológico, nesta perspectiva, está bem além do enfrentamento do trauma e dos fatores de adaptação uma vez que o ferido toma novamente nas mãos o que lhe aconteceu para fazer um novo projeto de vida. Utiliza a memória ferida para organizar um novo modo de viver, o que agora passa a ser um crescimento, uma maturação pós-traumática. O desenvolvimento não é mais o mesmo, pois houve uma catástrofe. Ocorre, na verdade, o que o autor denomina um neodesenvolvimento o qual contém na alma a fúria de consertar as coisas e as contas. Uma coragem que dá sentido ao sofrimento e o transcende, tamanha a necessidade de o ferido pensar em dias melhores.

Conforme Cyrulnik ${ }^{12,14}$, um ferido da alma, como se refere aos traumatizados, que não se torna resiliente não significa que seja incompetente ou que se entregue ao infortúnio. A dificuldade de retornar a um desenvolvimento pode significar uma fragilidade sua prévia ao trauma ou uma falha no ambiente para o acolhimento desse ser humano vítima de trauma e de suas narrativas que dão significado às adversidades. Quem possui a oportunidade interna e externa de exercitar reações resilientes conservou a esperança, sempre bem-vinda na trajetória da reformulação saudável de um novo viver. Além disso, segundo esse autor, quando aqueles que decidem as rotas políticas, sociais e de saúde aceitam dispor em redor dos que começaram mal (apoio social), um grande número de sujeitos magoados conseguem "metamorfosear-se" ou modificar os seus sofrimentos para deles fazerem uma obra humana apesar de tudo. Resiliência seria então a arte de velejar em torrentes e da metamorfose da dor para dar-Ihe significado. É a capacidade de ser feliz, mesmo quando existem feridas na alma. É tudo isto e muito mais, nos explica Boris Cyrulnik.

Yolanda Gampel, uma estudiosa da dor social, também se faz necessária citar aqui para pensar o fenômeno do trauma, sobrevivência psíquica, resiliência, crescimento pós-traumático e suas complexas inter-relações. É psicanalista residente em Israel, onde adquiriu experiência profunda com sobreviventes e filhos de sobreviventes do Holocausto. Entre algumas de suas valiosas contribuições está o conceito de objeto tesourizado, o qual contém a força para a resistência psíquica. Este não é um objeto transicional substituto materno, mas vai além. $\mathrm{O}$ objeto é um tesouro que ajuda a viver ${ }^{15}$.

Diante desse panorama teórico, o seguinte relato de caso tem o objetivo de proporcionar uma discussão sobre os caminhos da sobrevivência psíquica à resiliência a partir de um enfoque psicodinâmico. $\mathrm{O}$ caso foi selecionado durante supervisão das dificuldades enfrentadas em atendimento de psicoterapia de orientação analítica semanal, realizado por um terapeuta em um ambulatório de serviço psiquiátrico público por um período de aproximadamente 2 anos. Foi obtido do paciente termo de consentimento livre e esclarecido para 
participação em pesquisa sobre resiliência inserida em um projeto de pesquisa maior, aprovada conforme avaliação do Comitê de Ética da instituição a qual o serviço se vincula em parecer de no 878.763. Para preservar seu anonimato e impedir seu reconhecimento, dados e eventos de vida do paciente foram alterados com técnica de disfarce grosseiro buscando-se não comprometer o entendimento e a discussão do caso, conforme orientações de Gabbard ${ }^{16}$ para publicação de relatos. Ainda em virtude da preservação do anonimato do paciente, o ano e o local em que a psicoterapia foi realizada além de dados que possam identificar o terapeuta serão mantidos em sigilo.

\section{Caso clínico}

Alberto era um homem de 42 anos e de boa aparência que falava com desenvoltura, mostrando-se inteligente e articulado ao contar sua história. Era profissional do setor administrativo, área em que concluiu ensino técnico. Procurou atendimento médico por dificuldades para dormir e problemas de vida, sendo avaliado e então indicado psicoterapia de orientação analítica semanal. Alberto contava uma história de se sentir injustiçado durante toda a sua vida, trazendo relatos de vivências traumáticas muito dolorosas, mas sem demonstrar muito afeto, o que chamava atenção para o uso de isolamento afetivo. $\mathrm{O}$ contato inicial com o terapeuta era como se o mesmo fosse apenas um observador frio e inerte - um mero espectador de seus relatos. Essa forma de se relacionar com o terapeuta sugeria dificuldades em sua relação objetal com seu mundo interno e externo. Apesar disso, mostrava-se receptivo às intervenções do terapeuta, apresentando um bom pensar psicológico e predisposição para a reflexão de seus conflitos.

A injustiça que ininterruptamente o atormentava e o massacrava em ruminações nos últimos anos era um litígio envolvendo uma herança. Alberto era querido por um tio paterno que era rico e que pouco antes de falecer começou a dividir seus bens entre seus filhos e Alberto, que receberia uma valiosa sala comercial. Contudo, o tio logo faleceu sem conseguir preparar adequadamente a passagem da herança e seus filhos se aproveitaram e tomaram para si a sala. Alberto entrou em litígio para receber a herança prometida, mas sem sucesso. Nos primeiros meses de psicoterapia, contava e recontava em detalhes essa história, tendo sua pulsão de vida consumida por esse luto aparentemente inelaborável pela herança, cujos significados foram sendo compreendidos ao longo do tratamento. A herança parecia encobrir por deslocamento a figura do tio que representava sua única figura paterna, uma vez que o pai de Alberto abandonou a família quando ele ainda era criança. Parecia, assim, viver um luto pela perda do tio afetuoso e pelo pai abandonante, uma falha de figuras parentais interrompendo a passagem de Alberto para a vida adulta com modelos de identificação paternos, desde sua infância.

Embora apresentasse dificuldades para sobreviver psiquicamente a esse luto, orgulhava-se por ser um sobrevivente mesmo antes de ter nascido - resistiu a uma doença gestacional da mãe, que negligenciou tratamento adequado. Depois disso, contava que sobreviveu também aos abusos físicos da mãe que lhe batia muito a ponto de deixar marcas pelas surras com objetos pesados. Verbalizava as surras como sendo ataques 
de tortura da parte dela. A mãe era descrita como alguém que não tinha educação e que agia do jeito que ela achava que tinha que ser. Assim foi até crescer quando conseguiu impor respeito sendo agressivo. 0 pai, que era conivente com as agressões da mãe, abandonou cedo a família. Alberto manteve pouco contato com o pai e sua mãe morreu há anos por um problema de saúde. Conviveu com seu tio paterno com frequência na infância e adolescência e recebia dele alguma atenção. Seu tio acabou lhe servindo de modelo e inspiração ao longo de toda a sua vida. Alberto começou a trabalhar na adolescência em área administrativa e destacava-se por sua habilidade e dedicação com números, planilhas e programas de informática. Iniciou nesse período uso de drogas ilícitas não injetáveis.

Desde a adolescência era movido por uma fantasia de resgatar os outros do sofrimento e desamparo. Parecia inconscientemente tentar salvar a si mesmo através de projeção nos outros, em última análise tão desamparados quanto ele. Assim, não suportava ver algum amigo ou mesmo alguém desconhecido indefeso apanhando de forma injusta e por isso se envolvia facilmente em brigas perigosas para protegê-los. Era irônico e desafiador quando abordado por autoridades de segurança pública como se buscasse o castigo. Certa vez, ao defender um amigo numa briga, foi sequestrado e preso em cárcere privado por uma gangue marginal sendo torturado por dias de forma descrita como desumana. Durante os momentos de tortura reagia, fato que enfurecia ainda mais seus carcereiros resultando em mais agressões físicas. Após uma denúncia, foi finalmente libertado. A seguir ficou deprimido por um longo tempo quando então fez uso intenso de drogas ilícitas, até que conseguiu retomar e seguir sua vida sem haver realizado qualquer tipo de tratamento.

Após um período descrito como mais rebelde de brigas e comportamento desafiador na juventude, em meados da vida adulta parou, por conta própria, de se envolver em confrontos e de usar drogas. Contudo, seguiu sua vida com a sua antiga fantasia de resgatar os outros. Sem conseguir dizer "não" quando era solicitado a dar dinheiro ou a fazer um favor qualquer, acabava sentindo-se e de fato sendo usado e vitimado. Esse funcionamento parece ter sido promovido pelas marcas de injustiça experenciadas por Alberto, que o levaram a um padrão disfuncional de relacionamento interpessoal no qual se submetia e se revitimizava, dessa forma repetindo a vivência de que os outros são aproveitadores e torturadores, tal como sua mãe que o maltratava. Embora se sentisse vítima, agia de forma cordata e se deixava ser explorado, como quando facilmente se envolvia com quem sentia pena ou julgava menos favorecido em negociações nas quais sabia que seria explorado ou logrado. Isso, por fim, como num círculo vicioso, aguçava ainda mais sua sensação de injustiça e a percepção dos outros como aproveitadores e torturadores.

Em contrapartida, em outros momentos Alberto racionalizava esses sentimentos de injustiça e agia obtendo pequenos ganhos secundários, em particular no trabalho, fazendo os outros se sentirem enganados e explorados. Tais comportamentos encobertos e pouco relatados atuaram como fatores de resistência à mudança intrapsíquica e faziam o terapeuta se sentir ora como um malfeitor que não sopesava as injustiças que Alberto carregava em suas feridas da alma, ora como um cúmplice que se aliava a seus comportamentos de vitimização. 
Alberto casou-se e teve um filho. Sem se dar conta, tinha relacionamento distante da família por sua iniciativa, referia não receber deles atenção e apoio e manifestava na psicoterapia sentimentos de solidão. No plano profissional, embora exercesse muito bem sua função administrativa em uma grande empresa financeira, parecia funcionar em um nível inferior ao que poderia devido às ruminações frequentes que o atormentavam, aos comportamentos encobertos de ganho secundário e aos problemas na relação com figuras de autoridade. Sua família paterna era de ascendência indígena e Alberto valorizava essa cultura. Assim, tinha como passatempo o hábito peculiar de guardar, zelar e consertar com muita estima artigos indígenas que seu pai e tio guardavam, objetos aparentemente sem valor, mas repleto de significados para Alberto.

Usando-se como ferramenta de compreensão do caso o Diagnóstico Psicodinâmico Operacionalizado $(\text { OPD- } 2)^{17}$, observa-se que embora Alberto tivesse bons recursos de ego, apresentava um nível moderado de integração estrutural de sua personalidade, conforme aprofundado a seguir. Possuía um superego rudimentar e punitivo. Seus objetos internos não eram estáveis e integrados, havendo um medo central de perda do objeto, representado pelo pai abandonante; e idealização de alguns objetos, como do tio paterno. Seus limites do self não eram bem definidos e assim percebia os outros de forma mais estereotipada e fragmentada. Não experimentava a si próprio como agente regulador de suas ações, sentindo-se frequentemente controlado pelos outros. Tinha uma vida emocional intrapsíquica empobrecida, com dificuldade de tolerar, entender e expressar seus afetos, exercendo inconscientemente controle rígido sobre eles, especialmente sobre os afetos agressivos. Isso leva-o a um comportamento predominantemente submisso, masoquista e excessivamente cortês; ou, fortuitamente, a um comportamento impulsivamente agressivo. Devido a dificuldades de vinculação, agia parecendo não precisar dos outros, mas algumas vezes se aproximava das pessoas de forma velada para compensar sentimentos de solidão.

Alberto atribuía sua resistência ao sofrimento ao longo da vida a uma forte imaginação que lhe povoava a mente com frequência. Apesar de ser ateu, nesses momentos pensava em postulados espíritas e imaginava ter tido uma vida passada na qual era um bravo guerreiro indígena, rememorando histórias de seu tio. Era um forte, um resistente que venceu muitas batalhas. Isso sugere que a identificação com o tio, um objeto bom, aliado aos fragmentos resilientes de Alberto, mesmo que por vezes fantasiosos sob a forma de guerreiro, auxiliaram para que ele suportasse as dores e sobrevivesse e estruturasse sua vida com partes saudáveis.

Após um período de aproximadamente 2 anos de psicoterapia, evoluiu conseguindo simbolizar um pouco mais a dor pelo tio perdido e pelo pai abandonante e também sofrer menos pelo litígio da herança, agora um pouco mais destituída dos significados antes mais intensos. Além disso, foi ganhando consciência da sua responsabilidade em situações nas quais costumava se sentir vitimado e injustiçado ou atuando conflitos inconscientes, integrando um pouco mais seu self e objetos internos antes cindidos e fragmentados. Evoluiu conseguindo colorir um pouco mais sua vida afetiva, acessando e expressando melhor seus afetos, ganhando mais flexibilidade emocional.

Poderia se pensar que a capacidade de Alberto verbalizar com exuberância e detalhes seus traumas e 
fantasias na psicoterapia, aliada à capacidade de escuta do terapeuta bem como a intervenções que variavam de apoio a expressivas, agiram como tutores da resiliência. A narrativa repetida, a livre expressão de sua raiva e dos sentimentos amorosos em ambiente seguro parecem ter fornecido uma estrutura que propiciou Aberto retomar alguns fios de um desenvolvimento psíquico mais saudável, talvez em um movimento ainda tênue no sentido da resiliência.

\section{Discussão do caso}

Chama atenção na história de Alberto um contexto social de adversidades e traumas significativos que iniciaram já ainda em sua gestação. Na infância, deparou-se com uma mãe violenta, um ambiente social também violento e sem pilares emocionais de segurança em seu mundo, não havendo espaço para tutores de resiliência. Não bastassem esses infortúnios, foi marcado por uma experiência de torturas severas. Imerso em uma vida empobrecida de afetos e de relações pessoais significativas em sua história, ainda não havia enfrentado suas experiências traumáticas de forma positiva. Assim, à luz da literatura revisada e do estudo do caso, Alberto parecia adaptar-se como um sobrevivente, mas não como um resiliente.

Seguindo o modelo proposto por Cyrulnik ${ }^{12,18}$ para compreender o caso, os caminhos que prejudicaram a resiliência de Alberto perpassaram por déficit de recursos internos advindos de uma vinculação parental deficiente; traumas ao longo de toda a sua vida de diferentes formas e intensidades; e carência de encontros interpessoais e redes de apoio que possibilitassem criar uma nova narrativa de seus traumas - espaço esse que foi proposto por sua psicoterapia.

Até o momento da psicoterapia, não the havia sido possível "metamorfosear" sua dor em direção a uma vida mais feliz. Vivia preso em seu desamparo por ter sido negligenciado pelo pai e maltratado pela mãe. Depositava toda a sua esperança de reparação dos traumas passados no penoso e infrutífero litígio pela herança prometida pelo tio. Sobrevivia a essa perda, mas sem ter desenvolvido uma nova narrativa, um projeto de libertação saudável. Para escapar do passado de abandono e maus-tratos, parecia refugiar-se em uma idealização quase delirante de ser um bravo guerreiro, que validava em sua mente a narrativa de ter sobrevivido à doença gestacional que sua mãe negligenciou. De forma alternativa, acalentava-se cuidando com zelo e primor dos artigos indígenas de seu pai e tio como se fossem verdadeiros tesouros, que pareciam ajudá-lo em sua sobrevivência psíquica ao trazerem alguma estabilidade interna, seja por rememorarem aspectos idealizados de objetos internos, seja por reaproximá-lo de figuras abandonantes. Em outras palavras, esse aspecto de seu funcionamento poderia ser entendido como uma tentativa de resgate de suas boas experiências infantis ou como uma revitalização de partes de seus objetos bons. Desse modo, poderíamos pensar que esses pertences funcionavam como objetos tesourizados - que o ajudavam a viver - conforme proposto por Yolanda Gampel ${ }^{15}$ em sua larga experiência com pessoas traumatizadas.

A relação conturbada de Alberto com sua mãe e o pai negligente não lhe proporcionaram a construção de um apego seguro. Adotou como estratégia de sobrevivência na infância e vida adulta a idealização do tio, 
que é quem fez jus à sua fantasia de ser um bravo guerreiro. Em contraponto, em sua narrativa objetiva, Alberto descrevia, sem se dar conta, eventos que sugeriam um tio abandonante e não apoiador na sua juventudealguém que não acolheu genuinamente sua narrativa e que, portanto, não parece ter atuado como um tutor de resiliência. Sua fantasia e os objetos tesourizados ninguém Ihe tirava. Por outro lado, revivia continuamente um conflito em que nunca conseguia recuperar aquilo que the era de direito e foi tirado. Assim foi com o convívio com seu pai e mais tarde com a prometida herança de seu tio.

Devido ao nível moderado de integração estrutural e a seu superego rudimentar ${ }^{17}$, Alberto costumava pagar o preço da impulsividade em suas ações e distorcer as situações a favor dele, sendo projetivo. Assim, ainda carregava o peso de se sentir um injustiçado. Além dos mecanismos de projeção e identificação projetiva, em certo grau pode-se entender que Alberto manifestava também, como mecanismo de defesa imaturo, uma fantasia quase autística quando se refugiava em sua fantasia de ser um bravo guerreiro. Manifestava também mecanismos de defesa intermediários (neuróticos) como deslocamento, isolamento afetivo e formação reativa. Raramente, contudo, surgiam em alguns momentos mecanismos de defesa mais maduros, quando eventualmente sublimava seu desamparo exercendo com primor sua função laboral e sendo assim valorizado em seu trabalho; ou então sendo altruísta ao ajudar pessoas que lhe pediam ajuda de forma não abusiva.

O trabalho da psicoterapia deve seguir fornecendo as bases para uma melhor integração estrutural de Alberto, incluindo a introjeção de um superego mais flexível e o desenvolvimento de mecanismos de defesa mais maduros. Espera-se que, à medida que o trabalho de psicoterapia avançar, Alberto possa ter mais recursos internos para introjetar o papel exercido pelo terapeuta como tutor de resiliência, num caminho em que os processos vigentes que ainda o mantêm num estado de sobrevivência psíquica - com menor repertório de possibilidades e sentido para sua vida - sejam transmutados para um processo de resiliência. É um crescimento que, nas palavras de Baron ${ }^{19}$, produz "espaço para a vitalidade, a reconquista da possibilidade de se deixar marcar, matrizes de onde se poderia multiplicar a potência de agir -e, às vezes, de produzir alegria, adaptação ativa, encontro".

Alberto ainda carregava consigo feridas da alma não elaboradas, ou seja, não metamorfoseadas. Para metamorfoseá-las, Alberto precisaria seguir desenvolvendo a capacidade de entrar em contato com sua dor e de suportá-la sem isolamento afetivo - o que denotaria uma migração para uma posição depressiva, conforme a teoria de Melanie Klein. Alberto ainda projetava sua dor e sua fragilidade nos outros e vivenciava fantasias de salvação, em vez de investir recursos internos para metamorfosear e elaborar em si mesmo sua dor. Ou, ao invés disso, projetava seus sentimentos destrutivos nos outros e os vivenciava como perseguidores. Devido a falhas no ambiente para acolhimento de sua dor, Alberto viveu por muitos anos num mundo sem esperança, pobre de significados. A partir de seus recursos intrapsíquicose da construção de uma aliança terapêutica em que se sentiu acolhido e ouvido, Alberto foi conquistando espaço na psicoterapia para reconciliar-se com sua história e construir novas narrativas que the conferiram mais esperança, permitindo-lhe começar a tecer caminhos para a resiliência - caminhos esses que passarão pelo neodesenvolvimento de significados que lhe permitam ser feliz, mesmo apesar de suas feridas na alma. E a psicoterapia se propôs a ajudá-lo nesse processo. 


\section{Considerações finais}

O relato de caso ilustrou caminhos da resiliência a serem percorridos em psicoterapia quando, por motivos diversos, esse caminho não pôde ser percorrido sem ajuda profissional. É de fundamental importância podermos pensar no papel de tutor de resiliência exercido pelo psicoterapeuta nesse processo. Esse papel envolve um encontro emocionalmente genuíno e sensível de acolher a dor do paciente e de auxiliá-lo a tecer novas narrativas que produzam experiências de reparação e construam novas bases de segurança. Reinstaura uma perspectiva de futuro e de esperança em que, apesar das marcas passadas, o sujeito (re)adquire a confiança de que o mundo cuida, introjetando uma nova forma de olhar para si mesmo, abrindo novos caminhos para enfrentar seus traumas e interrompendo velhos automatismos defensivos. Promove o aflorar de um indivíduo com mais capacidade e maior repertório de possibilidades para viver e se desenvolver de forma mais livre, mais repleta de significados e sentido para sua vida, num verdadeiro processo de ressignificação simbólica. Esse é o caminho da resiliência.

É importante que o psicoterapeuta compreenda os fatores que não tornaram possível ao indivíduo percorrer o caminho da resiliência sem ajuda profissional. Esses fatores envolvem a avaliação dos recursos internos do sujeito; o tipo, intensidade, período do ciclo vital, contexto e significado dos traumas; e a rede social de apoio disponível e a respectiva capacidade de o indivíduo mobilizar esse apoio. A melhor compreensão desses fatores, à medida que a psicoterapia progride, permite ao psicoterapeuta exercer um papel de tutor de resiliência que atua nos aspectos mais sensíveis do sujeito que dificultam ou o impedem de (re) iniciar um desenvolvimento - um processo psíquico muitas vezes árduo e doloroso, mas que constitui um verdadeiro projeto de libertação, um "neodesenvolvimento".

O caminho da resiliência do paciente através da psicoterapia perpassa pela mente do psicoterapeuta, num processo intersubjetivo. Assim, cumpre lembrar que, para exercer o papel de tutor de resiliência, é importante que o psicoterapeuta busque seu próprio caminho de resiliência frente a seus traumas passados ou futuros, num processo de contínuo aprimoramento de sua capacidade de mediar as dolorosas narrativas de seus pacientes.

O progresso das pesquisas permitirá entender melhor quais fatores são mais importantes nos caminhos de resiliência frente aos traumas do ciclo de vida humana, tanto num contexto preventivo e de promoção de saúde em termos de políticas de saúde pública, quanto num contexto terapêutico, em que as psicoterapias têm destacada importância. Este relato de caso buscou ilustrar alguns desafios enfrentados nesse processo.

\section{Referências}

1. Souza MTS, Cerveny CMO. Resiliência psicológica: revisão da literatura e análise da produção científica. Interam. j. psychol. [online]. 2006;40(1):115-22. 
2. Maginness A. The development of resilience: a model. Tese [Doctor of Phyilosophy in Psychology] University of Canterbury; 2007.

3. Teche SP. Fatores ambientais e neurobiológicos associados ao Transtorno de Estresse Pós-Traumático e à Resiliência. Dissertação [Mestrado em Ciências Médicas: Psiquiatria] - Universidade Federal do Rio Grande do Sul; 2013.

4. Fonagy P, Steele M, Steele H, Higgitt A, Target M. The Emanuel Miller Memorial Lecture 1992: The theory and practice of resilience. J. child psychol. psychiatry allied discipl. 1994;35(Suppl. 2):231-57.

5. Vaillant GE. Involuntary coping mechanisms: a psychodynamic perspective.Dialogues Clin Neurosci. 2011 Sep; 13(3): 366-370.

6. Price JP. Cognitive schemas, defence mechanisms and post-traumatic stress symptomatology. Psychol Psychother. 2007 Sep;80(Pt 3):343-53.

7. Simeon $D$, Yehuda $R$, Cunill $R$, Knutelska $M$, Putnam FW, Smith LM. Factors associated with resilience in healthy adults. Psychoneuroendocrinology. 2007 Sep-Nov;32(8-10):1149-52.

8. Bonanno, GA. Loss, trauma, and human resilience: have we underestimated the human capacity to thrive after extremely aversive events? Am Psychol. 2004 Jan;59(1):20-8.

9. Walsh, F. Strengthening family resilience. New York: Guildford Press; 1998.

10. Duan W, Guo P, Gan P. Relationships among Trait Resilience, Virtues, Post-traumatic Stress Disorder, and Post-traumatic Growth. PLoSOne. 2015 May 1;10(5):e0125707.

11. Malgarim BG, Santana MRM, Machado AP, Bastos AG, Freitas LH. Resilience and psychoanalysis: a systematic review. Psico. 2018;49(2).

12. Cyrulnik B. Autobiografia de um espantalho: Histórias de resiliência: o retorno à vida. 1ạ ed. São Paulo: WMF Martins Fontes; 2009.

13. Arendt H. Homens em Tempos Sombrios. 1ạ ed. São Paulo: Companhia das Letras; 2008. p. 95

14. Cyrulnik B. O murmúrio dos fantasmas. São Paulo: Martins Fontes; 2005.

15. Gampel Y. I Was a Shoah Child. British Journal of Psychotherapy. 1992;8(4): 391-400.

16. Gabbard GO. Disguise or consent: problems and recommendations concerning the publication and presentation of clinical material. Int J Psychoanal. 2000;81(6):1071-86.

17. OPD Task-Force. OPD-2: Diagnóstico Psicodinâmico Operacionalizado: Manual de diagnóstico e plano de tratamento. Göttingen: Hogrefe\& Huber; 2017.

18. Cyrulnik, B. Falar de amor à beira do abismo. São Paulo: Martins Fontes; 2006.

19. Baron SC. Estratégias criativas de sobrevivência psíquica ao traumatismo insidioso de um cotidiano de adversidades. I Seminário Nacional sobre Estresse, Saúde e Trabalho: Magnitude, transcedência e vulnerabilidade. 2012; Rio de Janeiro, Brasil. Disponível em: http://www.senesat.uff.br/sandra.pdf. Acessado nov 2016. p. 3. 
Contribuições: Felipe de Luca Medeiros - Coleta de Dados, Conceitualização, Gerenciamento do Projeto, Investigação, Redação - Preparação do original, Redação - Revisão e Edição;

Bibiana Godoi Malgarim - Coleta de Dados, Conceitualização, Investigação, Redação - Revisão e Edição;

Lúcia Helena Machado Freitas - Coleta de Dados, Conceitualização, Investigação, Metodologia, Redação Revisão e Edição, Supervisão.

\section{Correspondência}

Felipe de Luca Medeiros

e-mail: deluka@gmail.com / e-mail alternativo: delucapsiq@gmail.com

\section{Bibiana Godoi Malgarim}

e-mail: bmalgarim@yahoo.com.br

Lúcia Helena Machado Freitas

e-mail: luciahelena.frei@gmail.com

Submetido em: 06/04/2018

Aceito em: 08/02/2019 